\title{
A Duck after Treatment for Extensive Organizing Pneumonia
}

\author{
Ryosuke Hamanaka, Kosaku Komiya, Kazufumi Hiramatsu and Jun-ichi Kadota
}

Key words: organizing pneumonia, cancer, nodule

(Intern Med 60: 1477-1478, 2021)

(DOI: 10.2169/internalmedicine.5855-20)
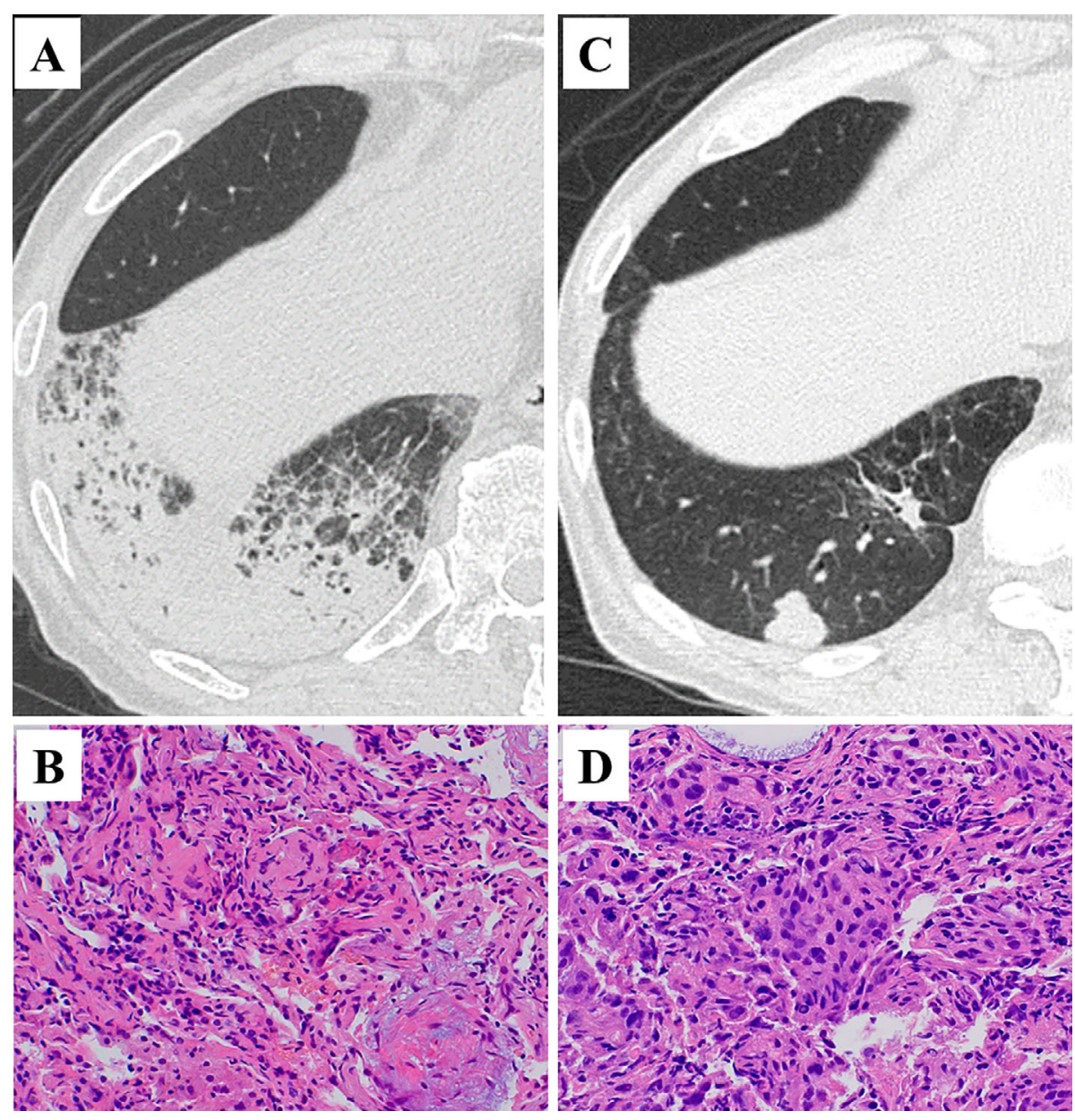

Picture.

A 69-year-old man visited our hospital due to persistent cough and sputum, and high-resolution computed tomography (HRCT) showed parenchymal exudates with groundgrass opacities in both lungs (Picture A). A transbronchial lung biopsy (TBLB) showed intra-alveolar organization with lymphocyte infiltration (Picture B). We diagnosed him with organizing pneumonia and treated him with $30 \mathrm{mg} /$ day of oral prednisolone. After treatment, most of the infiltrates observed on HRCT diminished, but a duck-shaped nodule appeared in the right lower lobe (Picture C). We re-performed 
a TBLB of the nodule, which revealed large-cell carcinoma with a high cytoplasmic-to-nuclear size ratio (Picture D). Although lung cancer is known to cause secondary organizing pneumonia occasionally (1), a case with a hidden nodule in the extensive organizing pneumonia has never been reported. Local immune responses to the tumor might be associated with the development of organizing pneumonia (2). When unresolved organizing pneumonia is encountered, aggressive diagnostic approaches are required.

The authors state that they have no Conflict of Interest (COI).

\footnotetext{
(C) 2021 The Japanese Society of Internal Medicine Intern Med 60: 1477-1478, 2021
}

\section{References}

1. Baha A, Yıldırım F, Köktürk N, et al. Cryptogenic and secondary organizing pneumonia: clinical presentation, radiological and laboratory findings, treatment, and prognosis in 56 cases. Turk Thorac J 19: 201-208, 2018.

2. Mao R, Zhang L, Hou J, Zou Y, Zhu L, Chen Z. Organizing pneumonia secondary to lung cancer of unknown primary site. Respir Med Case Rep 28: 100892, 2019.

The Internal Medicine is an Open Access journal distributed under the Creative Commons Attribution-NonCommercial-NoDerivatives 4.0 International License. To view the details of this license, please visit (https://creativecommons.org/licenses/ by-nc-nd/4.0/). 